Editorial

\title{
Urban Design and City Microclimates
}

\author{
Robert D. Brown \\ Department of Landscape Architecture and Urban Planning, Texas A\&M University, \\ College Station, TX 77840, USA; rbrown@arch.tamu.edu
}

Received: 13 November 2018; Accepted: 13 November 2018; Published: 15 November 2018

More than half of the people in the world now live in cities and this proportion is expected to continue to increase. Global Climate Change (GCC) and Urban Heat Island (UHI) intensification are making cities hotter places to live. Hot cities can have both a chronic and an acute effect on human health. Uncomfortably hot microclimates discourage people from spending time outdoors, resulting in various negative physiological and mental health issues. Heat waves are becoming more intense, more frequent, and are lasting longer than in the past, leading to acute health problems including hyperthermia and death. Urban designers require solid evidence about how to ameliorate or perhaps even reverse the trend towards hotter cities. They need evidence-based adaptation strategies for redesigning cities so that they will be more thermally comfortable every day, and safer during extreme heat events.

This Special Issue explored two important questions that are fundamental to designing thermally-safe cities: how does the urban environment modify microclimates; and how do urban microclimates affect the thermal comfort and health of urban residents? In contrast to the many studies that address these issues through modeling and simulation alone, all the papers in this Special Issue validated their work through on-site measurements. As we continue to strive to make cities more thermally comfortable and safer it is critical that our research results are not artifacts of a modeling system, but are, in fact, real. This can only be achieved through field measurements with carefully calibrated instruments that are used correctly. All the studies in this Special Issue have done this.

Wang et al. [1] measured the air temperature in the high-rise, compact city of Hong Kong through the collection of transverse data and used the results to validate a one-dimensional temperature model. They found that the transverse method measured air temperatures that were 1 to $3{ }^{\circ} \mathrm{C}$ higher than stationary measurements, suggesting that the latter method might be underestimating the urban heat island. Liu et al. [2] collected high-quality measurements of the physiological parameters of four subtropical tree species as well as their effect on the microclimate. They compared their results with simulations from the environmental modeling system ENVI-met, and identified some important discrepancies, most notably that the model over-estimated the leaf surface temperature. This kind of study is crucial for the development and fine-tuning of modeling and simulation systems. Lee et al. [3] conducted a detailed evaluation of how different shading strategies affect the thermal energy budget of people. They concluded that in hot sunny weather shade from a building was the most effective, followed by tree shade, and finally shade from an umbrella. They also pointed out that under cloudy conditions these rankings might change, suggesting further research is needed. This kind of research can be directly employed by urban designers and landscape architects in the design of urban outdoor spaces to that they will be more thermally comfortable for people.

Herdt et al. [4] measured the mesoscale climate of the Greater Toronto Area through the deployment of 53 weather stations across the city. They monitored conditions during the 2015 Pan American Games and identified areas of elevated heat and humidity. They used the human energy budget model COMFA to simulate the thermal comfort conditions of athletes and spectators during outdoor events, identifying a heightened risk of heat-related illness. Their data set provides a valuable 
resource into studying how the urban infrastructure affects the local microclimate. Hirabayashi et al. [5] developed a GIS-based version of the COMFA model to simulate the thermal comfort conditions along a section of the marathon route of the 2020 Olympic Games in Tokyo, Japan. This is an important innovation where a steady state model has been applied spatially across the landscape. They used measured data that was collected on the pre-anniversary of the marathon race as inputs to the model and simulated the effect of various physical site characteristics on thermal comfort levels. They identified sky view factor, air temperature, and solar radiation as factors that had a positive relationship with the energy budget, and estimated that the provision of shade would have the most beneficial cooling effect. Kosaka et al. [6] also studied the marathon route for the 2020 Olympic Games in Tokyo, but took the approach of mounting microclimate instruments to vehicles and driving along the marathon route at the rate of a marathon runner, to measure the conditions that a runner would experience throughout the race. This method of data collection is an important innovation as it provides an opportunity to apply a steady-state model through a landscape over time. They analyzed their data through application to the COMFA model and identified particularly hot, dangerous locations along the route. They suggested methods for cooling the hot spots, and quantified the cooling effect through modeling.

Nouri et al. [7] investigated the effects of a semi-deciduous tree species on thermal comfort in the urban heat island of Lisbon. They found physiologically equivalent temperature (PET) reductions of more than $15{ }^{\circ} \mathrm{C}$ during very hot summer days. They also found a reduction in PET of almost $3{ }^{\circ} \mathrm{C}$ during winter, a time when a higher PET would be desirable. Smith and Henriquez [8] analyzed how the physical characteristics of public spaces in Chillán, a city with very hot summer weather, affects the microclimate and consequently the thermal comfort of visitors. They identified solar radiation as the most influential factor in terms of thermal comfort, and the amount of solar radiation was a function of the sky view factor and the height to width ratio of the space.

This Special Issue has brought together eight excellent papers that have addressed the critical questions of how urban environments affect the microclimate, and how the microclimate affects the thermal comfort of people. The COMFA model was the most frequently used human energy budget model and solar radiation was determined to be the most important microclimatic element to modify. The information from these papers can be used to inform the design of urban areas so that they will be more thermally comfortable in hot weather and safer during heat waves.

\section{References}

1. Wang, X.; Li, Y.; Yang, X.; Chan, P.; Nichol, J.; Li, Q. The Street Air Warming Phenomenon in a High-Rise Compact City. Atmosphere 2018, 9, 402. [CrossRef]

2. Liu, Z.; Zheng, S.; Zhao, L. Evaluation of the ENVI-Met Vegetation Model of Four Common Tree Species in a Subtropical Hot-Humid Area. Atmosphere 2018, 9, 198. [CrossRef]

3. Lee, I.; Voogt, J.A.; Gillespie, T.J. Analysis and Comparison of Shading Strategies to Increase Human Thermal Comfort in Urban Areas. Atmosphere 2018, 9, 91. [CrossRef]

4. Herdt, A.; Brown, R.; Scott-Fleming, I.; Cao, G.; MacDonald, M.; Henderson, D.; Vanos, J. Outdoor Thermal Comfort during Anomalous Heat at the 2015 Pan American Games in Toronto, Canada. Atmosphere 2018, 9, 321. [CrossRef]

5. Hirabayashi, S.; Abe, T.; Imamura, F.; Morioka, C. Development of a Distributed Modeling Framework to Estimate Thermal Comfort along 2020 Tokyo Olympic Marathon Course. Atmosphere 2018, 9, 210. [CrossRef]

6. Kosaka, E.; Iida, A.; Vanos, J.; Middel, A.; Yokohari, M.; Brown, R. Microclimate Variation and Estimated Heat Stress of Runners in the 2020 Tokyo Olympic Marathon. Atmosphere 2018, 9, 192. [CrossRef] 
7. Santos Nouri, A.; Fröhlich, D.; Matos Silva, M.; Matzarakis, A. The impact of Tipuana tipu species on local human thermal comfort thresholds in different urban canyon cases in Mediterranean climates: Lisbon, Portugal. Atmosphere 2018, 9, 12. [CrossRef]

8. Smith, P.; Henríquez, C. Microclimate Metrics Linked to the Use and Perception of Public Spaces: The Case of Chillán City, Chile. Atmosphere 2018, 9, 186. [CrossRef] 